Fanum

Sociológico

\section{Forum Sociológico}

Série II

28 | 2016

Interculturalidade e educação

\title{
O ensino de Português na Ásia Oriental : de quem para quem
}

Portuguese teaching in Eastern Asia : from whom to whom

\section{Ânia Soeiro Matos}

\section{(2) OpenEdition \\ Journals}

\section{Edição electrónica}

URL: https://journals.openedition.org/sociologico/1436

DOI: 10.4000/sociologico. 1436

ISSN: 2182-7427

\section{Editora}

CICS.NOVA - Centro Interdisciplinar de Ciências Sociais da Universidade Nova de Lisboa

\section{Refêrencia eletrónica}

Ânia Soeiro Matos, «O ensino de Português na Ásia Oriental : de quem para quem», Forum Sociológico [Online], 28 | 2016, posto online no dia 31 dezembro 2016, consultado o 31 março 2022. URL: http:// journals.openedition.org/sociologico/1436 ; DOI: https://doi.org/10.4000/sociologico.1436 


\title{
O ENSINO DE PORTUGUÊS NA ÁSIA ORIENTAL: DE QUEM PARA QUEM PORTUGUESE TEACHING IN EASTERN ASIA: FROM WHOM TO WHOM
}

\author{
Ânia Soeiro Matos \\ universidade de Línguas Estrangeiras de Dalian, Faculdade de Espanhol e Português, Departamento de Língua Portuguesa
}

\begin{abstract}
Resumo
Ao longo deste artigo são analisados os processos de desenvolvimento da língua portuguesa e do seu ensino na Ásia Oriental, nomeadamente na República Popular da China, Japão e República da Coreia. Posteriormente, traça-se o quadro actual do Ensino da Língua Portuguesa na região, recorrendo, por um lado, a elementos quantitativos que nos permitem ter uma ideia da escala de como o português é tratado em cada contexto e, por outro lado, a elementos qualitativos que nos permitem ter um olhar mais minucioso da realidade para além dos números. O que encontramos são contextos com alguns pontos em comum, mas com muitas diferenças marcadas pela história de cada país, e das suas relações com os países de expressão portuguesa, e com a própria língua portuguesa.
\end{abstract}

Palavras-chave: ensino de PLE, China, Japão, Coreia do Sul

\begin{abstract}
This article analyses the development and teaching process of the Portuguese language in East Asia, namely in the People's Republic of China, in Japan and in the Republic of Korea. Further on in the article the current situation of the Teaching of Portuguese in the region will be discussed. Both quantitative and qualitative elements have been used to ascertain the scale at which Portuguese is considered and taught in each country. Moreover, in addition to the figures the qualitative elements provide a more detailed picture of this reality. We have observed contexts with some aspects in common, however with many differences stemming from the history of each country and its relation with the countries of Portuguese expression and with the actual Portuguese language.
\end{abstract}

Keywords: teaching Portuguese as a foreign language, China, Japan, South Korea

\section{Introdução}

O foco deste artigo situa-se no desenvolvimento do Ensino de Português Língua Estrangeira (EPLE) na Ásia Oriental, um espaço que tem merecido do mundo lusófono uma atenção progressivamente maior ao longo das últimas décadas, sobretudo devido ao interesse mútuo em cooperar nos âmbitos comercial e económico.

De forma a concretizar o que se entende por Ásia Oriental, referimos desde logo a proposta da Divisão de Estatística das Nações Unidas (United Nations Statistics Division, 2013), que define pragmaticamente a Ásia Oriental como sendo o território constituído pela República Popular da China (Regiões Administrativas Especiais de Macau e Hong Kong, bem como Taiwan, estão incluídas),
Mongólia, República Democrática da Coreia (Coreia do Norte), República da Coreia (Coreia do Sul) e Japão.

Neste caso, o nosso ângulo de análise circunscreve-se às realidades chinesa, japonesa e coreana, pelo facto de representarem conjunturas nas quais presentemente o EPLE adquire maior importância, até pela própria posição que estes países ocupam no pelotão da economia mundial e que se traduz numa aposta no ensino de línguas estrangeiras. Assim, procurar-se-á estabelecer a comparação de um conjunto de indicadores relativos ao EPLE nesta região, com o objectivo de analisar a sua evolução, e olhar globalmente para o perfil dos agentes do processo ensino-aprendizagem nesse canto do globo. Pretende-se, ainda, cartografar o percurso da língua portuguesa, de modo 
a compreender melhor a situação presente no âmbito do EPLE.

\section{A Língua Portuguesa, o EPLE, e a sua implementação na Ásia Oriental}

Vasco Graça Moura (2005), na publicação "Atlas de Portugal", refere que "em muitos pontos do globo, a língua portuguesa terá 'entrado e saído' com relativa precariedade", sendo que "em muitos ficou e ainda hoje perdura". Quanto à justificação para tal fluxo, o mesmo autor aponta para razões de "natureza histórica, política e administrativa, institucional, social, cultural e familiar", que o próprio caracteriza como evidentes, e que no seu conjunto promoveram condições para uma permanência que varia "em termos muito diferentes entre si".

Esta breve caracterização remete-nos para a universalidade da língua portuguesa e, simultaneamente, para a complexidade inerente ao alcance da sua introdução fora do espaço onde teve origem. Vasco Graça Moura (2005) propõe ainda como exercício que possamos imaginar "um missionário, ou um comerciante português a chegar às partes da China ou do Japão (...) e começarem a entregar-se à sua actividade, falando e fazendo-se entender". Apesar da aproximação entre o "eu" e o "outro" que esta ideia nos transmite, todos os factores que influem nesta relação abrem caminho a percursos diferentes da língua portuguesa no espaço asiático.

\section{A Língua Portuguesa e o EPLE na China}

Quando falamos das relações sino-portuguesas, estão em equação mais de 500 anos de história. Desde a chegada de Jorge Álvares em 1513 à Ilha de Lingding (内伶仃岛), e da consolidação da administração portuguesa em Macau, a China e o mundo lusófono partilham um passado, um presente, e trabalham no sentido de construir um futuro através de uma estreita cooperação. A análise do ensino da língua portuguesa neste artigo não contempla o período em que Portugal administrava o território macaense, pois para todos os efeitos o território era oficialmente português.

Nesse sentido, em território chinês, só após a fundação da República Popular da China, em 1949, é que se dá uma gradual aposta no ensino de algumas línguas estrangeiras. Foi preciso esperar até 1960, em Pequim, para despontar oficialmente o primeiro curso de português no Instituto de Radiodifusão da China, actual Universidade de Comunicações da China (CUC), aquando do estabelecimento formal do seu Departamento de Línguas Estrangeiras (Ran, 2006; Yan, 2008). Orientado pela professora brasileira Mara Mazozini, este primeiro curso tem a duração de quatro anos e dele fazem parte 23 alunos, embora apenas 18 o concluam (Yan, 2008).
Posteriormente abrem cursos de português no Instituto de Línguas Estrangeiras de Pequim (hoje em dia, Universidade de Estudos Estrangeiros de Pequim/ BFSU $^{1}$ ) ainda na década de 1960 , e na Universidade de Estudos Internacionais de Xangai $^{2}$ na década de 1970, que se juntam ao Instituto Politécnico de Macau e à Universidade de Macau como únicas instituições com oferta de PLE no Ensino Superior chinês (Yuan e Água-Mel, 2012).

Ran (2006: 4) esclarece, a este propósito, que entre as décadas de 1970 e 1990 a língua portuguesa "era principalmente ensinada visando o seu uso na área da diplomacia na China Continental", um paradigma que apenas mudou em finais da década de 1990, e sobretudo a partir de meados de 2000, quando "[a] aprendizagem do Português passou duma necessidade meramente política para um instrumento útil e importante para entrar no mundo lusófono, nomeadamente na área da economia".

A oferta de PLE aumenta, assim, de forma praticamente desenfreada na China a partir da década passada, mudando o panorama da oferta curricular drasticamente. $O$ que encontramos actualmente é um universo documentado de 26 instituições de Ensino Superior que oferecem um programa curricular de EPLE, o que representa um acréscimo de 21 Universidades face a aproximadamente 10 anos atrás. Este crescimento estará longe de ser sustentado, mas visa suprir as necessidades de procura e oferta que existem para a língua portuguesa. Soares (2013) refere a este propósito, citando o Prof. Carlos Ascenso André, que não são 26 mas 28 as Instituições que ensinam português, para sensivelmente 1350 alunos. Segundo a mesma fonte (2013), "há mais de 100 docentes a leccionar português no Ensino Superior. É um corpo muito jovem, 65\% dos professores são chineses [35\% são portugueses ou brasileiros] e têm problemas de formação".

\section{A Língua Portuguesa e o EPLE no Japão}

Tal como a sua vizinha China, o Japão tem uma longa história com o mundo lusófono. Reconhecidos como os primeiros europeus a chegar ao Japão (Hall, 1991; Mason, 1997), os portugueses estiveram em contacto próximo com os japoneses durante aproximadamente 100 anos, até à entrada em vigor da política sakoku (鎖国) por parte do bakufu Tokugawa (徳川幕府)，que interdita a presença de todos os estrangeiros - excepto os holandeses em Nagasaki (長崎) - no Japão (Hall, 1991).

Esta proximidade possibilitou mais do que meras trocas comerciais ou conversões religiosas. Araújo (2008) pondera sobre as trocas de itens lexicais entre o idioma português e o japonês, citando Fonseca (1985), e refere um universo de aproximadamente quatro mil palavras de origem portuguesa que terão utilização na língua japonesa, 
termos esses que passam, em primeira instância, por um processo de nativização e apropriação. Entre esses itens destacam-se pan (パン), botan (ボタン) ou kasutera (カステラ), cuja etimologia é pão, botão e castela (vulgo pão-de-ló), reflectindo a introdução de novas práticas e conceitos relacionados com a culinária e o vestuário trazidos pelos portugueses durante esse século caracterizado pela aproximação de culturas.

Apenas mais tarde, a partir de meados do século XIX, após a reabertura do Japão ao exterior, um novo fulgor é vivenciado pela língua portuguesa no país do sol nascente, sublinhado pela chegada do professor João Abranches Pinto, em 1918, e dois anos mais tarde com a inauguração do primeiro curso universitário de Língua e Cultura Portuguesas na Universidade de Estudos Estrangeiros de Tóquio (Araújo, 2008).

O ensino da língua portuguesa no Japão tem uma particularidade que o torna essencialmente diferente dos restantes Estados da Ásia Oriental, e mesmo de muitos outros Estados a nível mundial. O que testemunhamos no Japão é um ensino de português que vai ao encontro da configuração social única do Japão, definida pelas vagas de emigração de nipo-brasileiros do Brasil para solo nipónico: por um lado, encontramos em algumas instituições o ensino da língua portuguesa no Ensino Fundamental e Médio - ou seja, na aprendizagem básica e matricial da formação dos indivíduos - e, por outro lado, vemos uma forte presença do ensino do português no Ensino Superior.

De uma análise ao sítio da Embaixada do Brasil em Tóquio ${ }^{3}$ emerge o peso que o ensino da língua portuguesa tem para as comunidades nipo-brasileiras. Podemos conferir que existem quarenta e cinco escolas brasileiras homologadas no Japão, com intervenção em diferentes níveis do sistema de ensino, mas cuja acção é visível sobretudo no Ensino Fundamental ( 6 aos 12 anos) e Ensino Médio (12 aos 18 anos).

No que diz respeito ao Ensino Superior no Japão, o ensino da língua portuguesa reflecte os desenvolvimentos sociais mais recentes do país, embora não esqueça o peso histórico da presença portuguesa no Japão, sobretudo pré-Tokugawa. Isto significa que encontramos uma tendência maior para privilegiar a variante brasileira da língua portuguesa, sem ignorar no entanto a existência de alguns cursos, em menor número, dedicados ao português europeu.

Rocha (2013), citando dados fornecidos pelo IPOR $^{4}$ referentes a 2011, menciona a existência de 31 universidades japonesas que desenvolvem cursos de língua portuguesa, estando matriculados 5035 alunos em diversos níveis de fluência linguística. Rocha (2013) avança ainda que em apenas 5 destas universidades existem departamentos dedicados aos estudos luso-brasileiros, leccionando língua portuguesa docentes de três nacionalidades: 52 professores japoneses, 19 brasileiros e 3 portugueses.

O Camões - Instituto da Cooperação e da Língua, I.P. (Instituto Camões, 2015) promove o ensino da língua portuguesa conjuntamente com três instituições japonesas de Ensino Superior, nomeadamente a Universidade de Osaka, a Universidade de Quioto - não confundir com a Universidade de Estudos Estrangeiros de Quioto (UEEQ) -, bem como a Universidade de Estudos Internacionais de Kanda.

\section{A Língua Portuguesa e o EPLE na Coreia}

Atendendo à caracterização da história da língua portuguesa nos Estados que constituem a Ásia Oriental, não será surpreendente verificarmos que a Coreia assume uma posição notavelmente distinta no que diz respeito ao ensino da língua portuguesa quando comparada com os seus vizinhos, quanto mais não seja por ser patente, pela sua conjuntura, uma superficialidade de relações culturais que se reflectem no peso que a língua portuguesa tem no sistema de ensino coreano.

Essa (ausência de) importância e frugalidade do ensino de língua portuguesa na Coreia foram inclusivamente assumidas pelo ex-embaixador de Portugal em Seul, o Dr. Henrique Silveira Borges, mesmo que tenham sido envidados esforços no sentido de melhorar esse panorama com a assinatura, em 1990, de um acordo de cooperação cultural entre Portugal e a República da Coreia (Colaço, 2008).

O que encontramos na Coreia, em síntese, é o ensino de língua portuguesa circunscrito a duas Universidades: a Universidade de Estudos Estrangeiros de Hankuk e a Universidade de Estudos Estrangeiros de Busan.

A primeira, pelo que nos é dado a conhecer no seu sítio oficial ${ }^{5}$, possui dois campus, ambos com oferta no ensino de português: um deles, situado em Seul, acolhe a Faculdade de Estudos Ocidentais, e refere a existência de um departamento de português autónomo, que assume treinar "continuamente profissionais para carreiras em Moçambique, Angola e Brasil" (Universidade de Estudos Estrangeiros de Hankuk, 2015a); o segundo, em Yongin, baptizado de campus global, é casa da Faculdade de Idiomas, que tem como missão "revelar capacidades de cada aluno e aumentar sua produtividade nos estudos em (...) português (...), criando assim profissionais coreanos de alto nível com capacidade de criação e liderança global" (Universidade de Estudos Estrangeiros de Hankuk, 2015b).

No caso da Universidade de Estudos Estrangeiros de Busan, também é dado a conhecer no seu sítio oficial que o departamento de português está inserido na Faculdade de Estudos Ocidentais e, aqui, a única informação presente sobre a acção 
do departamento tem contornos algo curiosos: "o departamento de português está focado em fornecer educação sistematizada de modo a melhorar as competências linguísticas dos estudantes de português, [e] (...) cultivar peritos internacionais em cultura local e contextos dos países da América Latina, como Angola e Brasil, que estão a emergir como gigantes económicos na região" (Universidade de Estudos Estrangeiros de Busan, 2015).

Em jeito de comparação, salta à vista, de imediato, que o nome de Portugal está ausente da informação contida na descrição dos vários departamentos. Ambas as Universidades, e respectivos departamentos, focam-se em Angola e Brasil - a UEEH também refere Moçambique - ao qual não será alheio o potencial económico desses Estados-membros da CPLP, algo que é inclusive sublinhado pela UEEB. De resto, não se pode deixar de mencionar o lapso geográfico da UEEB que coloca Angola na América Latina, o que veicula uma imagem pouco consentânea com o famoso nível académico sul-coreano.

Esta negligência poderá ser uma das razões pelas quais nos é difícil encontrar informação sobre o contexto de ensino local, não sabendo ao certo quantos alunos estudam português, quem são os professores, quais são as dificuldades encontradas.

\section{Exemplos da estrutura e funcionamento de universidades na Ásia Oriental}

Nesta parte, o desafio passa por abreviar o objecto de análise, partindo da parte para compreender o todo, ou seja, propomos analisar como é que três universidades, uma de cada país, estão organizadas, quem são os docentes e os aprendentes, e como é o ensino de PLE.

Para o efeito, foram utilizados dois métodos distintos de recolha de dados: pesquisa (e análise) documental e entrevista. Procurou-se recolher a maior quantidade possível de informação sobre as instituições em questão, bem como complementá-la através do contributo de informantes - que permanecerão anónimos a seu pedido, e serão referidos doravante como X (número) - com experiência no Ensino Superior asiático.

Não tendo sido possível realizar entrevistas ou questionários a responsáveis da Universidade de Estudos Estrangeiros de Quioto, fomos constrangidos a realizar uma recolha e análise documental tão profunda quanto possível.

Universidade de Línguas Estrangeiras de Dalian (DLUFL/ULED)

A Universidade de Línguas Estrangeiras de Dalian (DLUFL) iniciou a sua actividade em EPLE no ano lectivo de 2008/09. O curso de Licencia- tura encontra-se dividido em 4 anos, estando prevista a opção para prosseguir os estudos em Mestrado a partir do ano lectivo 2016/17. O PLE não tem um departamento completamente autónomo, encontrando-se agregado ao Departamento de Espanhol.

A DLUFL é uma Universidade com tradição no ensino de algumas línguas estrangeiras, sobretudo Japonês, Coreano e Russo, e procura desenvolver a sua actividade de forma apoiada também no ensino da língua portuguesa. É importante para a Universidade que os seus professores, sejam eles falantes nativos ou chineses, procurem ter formação avançada.

Actualmente estão sob contrato sete professores chineses e quatro leitores estrangeiros (três portugueses e um brasileiro). Os professores chineses, normalmente, leccionam sobretudo disciplinas de gramática, tradução e interpretação, cabendo aos leitores portugueses matérias do foro cultural e das competências comunicativas (quer de produção, quer de recepção). É de referir que dois dos professores chineses contratados pela Universidade não estão de momento a leccionar por razões de ausência no estrangeiro, em trabalho para o Instituto Confúcio. Deve-se acrescentar que é comum, segundo os informantes $\mathrm{X} 1$ e $\mathrm{X} 2$, os professores chineses ausentarem-se durante um ano - ou mais - para estudarem fora do país, normalmente em Portugal. A título de exemplo, o informante $X 1$ estudou na Universidade do Minho, enquanto o informante X2 realizou o seu Mestrado em Coimbra.

As faixas etárias aos quais os docentes pertencem não são semelhantes. De acordo com o informante $\mathrm{X} 3$, algumas universidades chinesas assumem a prática de contratar professores com bastante experiência - alguns deles, inclusivamente, após já se terem aposentado - de modo a conferir prestígio ao curso e equilibrar a eventual inexperiência do corpo docente. Há na DLUFL dois professores com mais de 60 anos, um na faixa etária dos 50, a maioria tem entre 28 e 35 anos, e existem ainda dois professores com menos de 27 anos.

No que diz respeito à experiência, a grande maioria tem entre 2 e 5 anos de prática na área do EPLE. Paralelamente, ao nível do currículo académico, apenas um professor tem Doutoramento (havendo ainda um doutorando), existindo seis mestres, e uma mestranda. Ainda de referir é a questão dos leitores que aparentemente fará de Dalian uma raridade no Ensino Superior chinês: de acordo com os informantes X2 e X3, é bastante difícil contratar leitores estrangeiros, mas a DLUFL consegue ter quatro nos seus quadros. A maioria das Universidades tem somente um leitor, e não raras vezes há anos lectivos em que nem um é possível contratar. Esta questão não se deverá a limites orçamentais, mas à dificuldade de angariar leitores, sobretudo pela 
complexidade de estabelecer uma rede de contactos rica com profissionais qualificados.

Mudando o foco para os aprendentes, desde 2008/09 até 2014/15, entraram na DLUFL 30 alunos em cada ano lectivo. As turmas, geralmente, são apenas compostas por alunos de nacionalidade chinesa, sendo que no $2 .^{\circ}$ ano é possível aos aprendentes, ao abrigo de um protocolo com a Faculdade de Ciências Sociais e Humanas da Universidade Nova de Lisboa (FCSH - UNL), estudar em Portugal. Os aprendentes que decidem ir para Lisboa podem, a partir do $3^{\circ}$ ano, permanecer na $\mathrm{FCSH}$, estudar na Universidade de Aveiro ou regressar a Dalian. Ademais, os aprendentes podem escolher apenas ir para Portugal no $3.0^{\circ}$ ano, estando de momento essa opção restrita ao estudo na Universidade de Aveiro, onde têm a oportunidade de completar a Licenciatura e prosseguir para o $2 .{ }^{\circ}$ ciclo de estudos.

O número de aprendentes por turma é, pela razão supracitada, pouco uniforme, e o nível dentro de cada grupo é também heterogéneo. Para aumentar ainda mais a complexidade salienta-se que ao abrigo de protocolos com a Universidade de Estudos Estrangeiros de Tianjin (TFSU) e com o Instituto de Línguas Estrangeiras Jilin Huaqiao (HQWY) é possível a inclusão de alguns aprendentes dessas instituições nas turmas de português da DLUFL.

Ainda não existe uma grande dinâmica no que diz respeito à promoção da língua portuguesa, e da licenciatura de português, quer no campus universitário como fora deste, faltando por exemplo uma maior proactividade na realização de eventos ou concursos, ou mesmo de uma semana cultural.

Universidade de Estudos Estrangeiros de Quioto (KUFS/UEEQ)

Uma das instituições japonesas em maior destaque é a Universidade de Estudos Estrangeiros de Quioto, uma das previamente mencionadas - e restritas - instituições com departamento de estudos luso-brasileiros, e com protocolos de intercâmbio com a Universidade de Coimbra, Universidade de Brasília, Universidade de São Paulo e Universidade Federal Fluminense.

O seu papel na divulgação e desenvolvimento da língua portuguesa no Japão está bem documentado. O Departamento de Estudos Luso-Brasileiros da UEEQ tem um sítio oficial ${ }^{6}$ com alguma informação sobre a sua actividade, na qual está incluída a organização do tradicional "Concurso de Eloquência de Língua Portuguesa para Estudantes Universitários Japoneses"7.

Uma das figuras responsáveis por este dinamismo é o Professor Ikunori Sumida. Nos parágrafos que se seguem, partindo do artigo do Prof. Sumida que sintetiza a sua apresentação no I SIMELP (Simpósio Mundial da Língua Portuguesa), tentar-se-á analisar o programa curricular em vigor na UEEQ.
Desde logo Sumida (2008) adianta que o Departamento de Estudos Luso-Brasileiros (vulgo DELB) foi fundado em 1967, por altura de uma época de robusta internacionalização do Japão, tendo o Mestrado em Estudos Luso-Brasileiros tido a sua primeira edição em 1971. Em Maio de 2008, o DELB tinha nos seus quadros 17 docentes $^{8}$, que ensinavam português a 272 alunos (mais 3 de Mestrado e outros 3 de Doutoramento), com 67 alunos no $1 .^{\circ}$ ano, 70 no $2 .^{\circ}$ ano, 81 no $3 .^{\circ}$ ano e 54 no $4 .^{\circ}$ ano. Independentemente de não haver um termo de comparação, os dados revelam alguma consistência, e indicam que um número considerável de alunos progride e conclui os seus estudos de língua portuguesa na UEEQ.

Relativamente ao programa curricular em vigor, Sumida (2008) afirma que este se pauta pelo "equilíbrio da preparação dos discentes na sua competência linguística quer em Português Brasileiro (PB), quer em Português Europeu (PE), sem esquecer a língua portuguesa em África e na Ásia", referindo ainda que o programa das disciplinas segue os princípios orientadores do "Quadro Europeu Comum de Referência para as Línguas". Ademais, Sumida (2008) aponta como principal objectivo do currículo do primeiro ano a aprendizagem do português prático e a cultura dos países lusófonos, acrescentando que o facto de ser a primeira língua estrangeira que muitos alunos aprendem - com excepção do inglês - promove que no ano inicial do curso os aprendentes tenham de adquirir as noções básicas de Fonética, Morfologia e Sintaxe, enquanto a partir do segundo ano, para além de Linguística e Literatura, os aprendentes são estimulados com temas da actualidade dos países lusófonos. É de salientar que ao longo dos quatro anos do curso as disciplinas obrigatórias incluem o estímulo de diversas competências quer ao nível da produção como da recepção em língua portuguesa.

Um dos aspectos mais inovadores, porém, é o chamado projecto CALL (Computer Assisted Language Learning), que consiste em aulas de laboratório, obrigatórias em todos os departamentos da UEEQ, e que visam facilitar, neste caso, a aprendizagem da língua portuguesa através das novas tecnologias (Sumida 2008). O "CALL - Português I", a título de exemplo, tem como objectivo "o contacto inicial com a Fonética da língua portuguesa, nomeadamente a aquisição de fonemas e a apresentação das principais variantes do português" (Aires, Iyanaga, e Muramatsu, 2008), tendo os seus autores produzido ainda um manual - Portufone vocacionado para falantes nativos de japonês, em jeito de programa informático.

O DELB da Universidade de Estudos Estrangeiros de Quioto pode ser considerado, por esta descrição que é aqui feita, um paradigma do ensino da língua portuguesa na Ásia, não só pela sensibilidade e preocupação na elaboração do programa curricular 
e dos materiais didácticos, bem como por todo o conjunto de iniciativas, previamente descritas, que promovem a língua e a cultura dos países lusófonos.

Universidade de Estudos Estrangeiros de Hankuk (HUFS/UEEH)

Para conhecer um pouco melhor a realidade sul-coreana, foi realizada uma entrevista por escrito a um informante anteriormente ligado à Universidade de Estudos Estrangeiros de Hankuk (HUFS/UEEH). Este informante - doravante X4 - tem uma leitura bastante crítica das diferenças que encontrou entre o ensino da língua na Europa e na Coreia do Sul, referindo que:

\footnotetext{
"a diferença mais drástica terá a ver com o contraste entre a dedução e a indução: ao passo que nas culturas ocidentais modernas, usualmente, o ensino da língua é feito através de métodos comunicativos, novas situações de comunicação, de cultura integrada e construindo-se novos discursos a partir de blocos primários, a esmagadora maioria do ensino das línguas na Coreia do Sul é feita através de métodos repetitivos, de indução, de quadros comunicativos algo desfasados da realidade e artificiais".
}

Ademais, pela estrutura do curso de Língua Portuguesa na HUFS, X4 refere que o leitor apenas se cingia a aulas de comunicação oral, tendo com professores coreanos as aulas de "compreensão gramatical, escrita, tradução (...)", apontando a "falta de comunicação e mesmo colaboração entre os professores coreanos e os leitores nativos das línguas, situação sentida através dos vários departamentos $(\ldots)^{\prime \prime}$ como um dos maiores problemas para quem ensina PLE na HUFS.

Em termos de aprendentes, X4 menciona que por ano, cada turma teria "cerca de 20 a 30 alunos. Poderia ter até quatro turmas, duas em Seul, duas em Yong-In". Quanto às suas funções, que já referimos cingirem-se mais às competências orais, de produção e recepção, admite que as partilhava com "outro professor, cidadão brasileiro, de larga experiência (...)", propondo-se a "servir de termo de comparação com a norma brasileira, expondo através dos mais diversos materiais e situações à vivência da realidade de Portugal".

X4 afiança ainda que as suas aulas eram ministradas apenas aos aprendentes dos dois primeiros anos do curso (que no total teria quatro anos), deixando os aprendentes de ter contacto com falantes nativos nos derradeiros anos do curso da HUFS. X4 avalia esta situação "como paradoxal ou mesmo ridícula numa organização equilibrada dos processos de aquisição e aprendizagem de uma língua estran- geira", afirmando também que estaria "totalmente fora de questão uma discussão sobre esse assunto que envolvesse os próprios professores nativos, ou até as instituições com as quais colaboravam".

No que diz respeito à caracterização dos próprios aprendentes, $\mathrm{X} 4$ traça um cenário algo negro relativamente aos finalistas e às suas competências linguísticas:

\footnotetext{
"mais de $50 \%$ [dos aprendentes que estavam no último ano do curso] não haviam atingido sequer um nível A1 [do QECR] em todas as competências. Alguns eram capazes de manter uma conversa básica de circunstância, ou repetir discursos previamente memorizados (tal como um discurso sobre a cultura portuguesa, uma letra de fado, ou algo similar), mas não encetar um novo diálogo".
}

X4 refere existirem "excepções, claro está, e mesmo alguns alunos brilhantes que procuravam uma autonomia total na aprendizagem do português, que se revelaria em excelentes conhecimentos da língua ou pelo menos na sua possibilidade de comunicação" dos quais excluía um caso particular que mencionámos num ponto anterior: "cidadãos coreanos nascidos ou educados durante longos anos no Brasil, de que havia um número significativo (no fundo, eram mais 'brasileiros' até pelos comportamentos culturais e proficiência da língua, do que 'coreanos')".

Uma explicação para este fraco desempenho trivializado na aprendizagem da língua portuguesa pode ser atribuído a um factor sociocultural, que X4 subscreve dizendo serem "os anos universitários dependendo do curso e perspectivas profissionais, naturalmente, mas generalizo - os únicos em que se pode não usar uniforme, vestirem-se como bem entendem, pintar o cabelo de azul, etc.", em suma, em que é permitido aos alunos coreanos "terem liberdade", por contraste ao seu percurso escolar anterior, caracterizado por um grande rigor e pressão para entrar na Universidade, o que poderá levar posteriormente a uma "certa lassidão nos estudos, mormente quando dizem respeito às línguas".

\section{Conclusões}

A realidade da Ásia Oriental face ao EPLE não é homogénea, revelando características próprias de cada Estado-Nação, com raízes na história individual partilhada com os países de expressão portuguesa.

No caso da China vemos que a conjuntura económica favorável, e a aposta no carácter utilitário da língua portuguesa como uma ferramenta que garante empregabilidade "no jornalismo, na diplomacia e nas empresas" (Soares, 2013), propiciam o aparecimento de cada vez mais instituições que 
oferecem a língua portuguesa nos seus currículos. Embora este processo nem sempre seja sustentado e com a qualidade desejada, algumas instituições, como a DLUFL, parecem investir cada vez mais no desenvolvimento dos seus recursos humanos, para que consequentemente o ensino evolua para os padrões desejados por todos os responsáveis, e sobretudo pelos aprendentes de hoje, que em muitos casos serão os professores de amanhã.

Em relação ao Japão, presenciamos um EPLE com grande enfoque na variante brasileira da língua portuguesa. A este facto não serão alheios os processos de diáspora que criaram novos desafios - nomeadamente no sector da Educação - para as comunidades nipo-brasileiras que vivem no Japão. Observamos um EPLE que tem origem no ensino básico, e não apenas no ensino superior, e que apesar de não estar a crescer a nível universitário, se encontra a crescer no ensino fundamental e médio, suprindo as necessidades educativas dos filhos dos Dekasseguis ${ }^{9}$. Encontramos neste país um nível de organização de ensino muito evoluído, com uma longa e rica história no Português Língua Segunda e Estrangeira, e que servirá de exemplo para a região em termos de meta qualitativa a atingir.

Por último, a Coreia aparenta ser um caso em que a perspectiva de apresentar o Português unicamente como um meio para realizar negócios com países emergentes de expressão portuguesa, colocando um excessivo peso no previamente referido carácter prático do ensino da língua, acaba por asfixiar o contexto do EPLE. As instituições, pelo que pudemos aferir, não garantem uma qualidade de ensino exemplar, o que terá reflexo nas competências dos aprendentes sul-coreanos e no desenvolvimento do PLE na Coreia. Além disso, a falta de ligação cultural entre o mundo lusófono e a Coreia, e os vínculos desta com países de outras esferas linguísticas acaba por secundarizar a necessidade de desenvolver o PLE no país, sendo o Português uma nota de rodapé em comparação com o que encontramos na China e no Japão.

Em termos comparativos, o Japão conta com 31 Universidades que ensinam PLE, enquanto a China tem 26. No início do século existiam apenas 5 Universidades em território chinês, e duas delas situavam-se em Macau. Esse número é, hoje, mais de 5 vezes maior. No caso da Coreia, apenas existem duas Universidades com PLE. A demografia não explica tudo, até porque a Coreia tendo apenas sensivelmente menos de metade da população do Japão, tem 15 vezes menos instituições que ensinam PLE.

Um dado curioso, é que a China tem bastantes mais professores de PLE do que o Japão, apesar do menor número de cursos e de alunos. Uma das ideias que estará por trás desta diferença passará pela aposta na quantidade de docentes para colmatar algumas insuficiências a nível de formação de professores. O rácio de professores nativos e estrangeiros é relativamente semelhante, 30\% para $35 \%$, respectivamente. Este valor ligeiramente superior por parte da China pode ser justificado também pela tentativa de arranjar docentes com formação específica, e não havendo no próprio país em número suficiente, recruta-se no exterior.

Quanto aos aprendentes, o Japão tem uns avassaladores 5035 alunos, para os 1350 da China. Estes dados podem ser lidos de várias maneiras. Dada a proximidade do Japão com o mundo lusófono, até pela importante comunidade nipo-brasileira que ali vive, é normal que haja um número superior de alunos. Além disso, o Japão é uma das potências económicas mundiais, com interesses no Brasil e nos países africanos em desenvolvimento, como Angola e Moçambique. Na China, parece-nos haver ainda algum desconhecimento sobre o potencial da língua portuguesa por parte do público pré-universitário chinês. Muitos alunos referem, informalmente, que não conheciam nada sobre Portugal ou sobre o Brasil antes de entrarem no curso, o que poderá condicionar estes valores.

A maior semelhança entre estes contextos assentará, possivelmente, na tentativa de instrumentalização da língua portuguesa para intervir no sector dos negócios, particularmente com os países emergentes de língua oficial portuguesa. Esta disposição, no entanto, não será exclusiva da Ásia Oriental, embora aqui assuma uma importância fundamental pelo poderio económico dos países desta região e pela sua necessidade de competir não só entre si, como com outras potências económicas inter-regionais, funcionado a língua portuguesa como uma ponte privilegiada para um mundo com mais de 250 milhões de falantes.

\section{Notas}

1 北京外国语大学 ou Beijing Foreign Studies University (BFSU)

2 上海外国语大学 ou Shanghai International Studies University (SISU)

3 Disponível em http://www.brasemb.or.jp/portugues/

4 Instituto Português do Oriente, disponível em http:// ipor.mo/

5 http://www.hufs.ac.kr/

6 Disponível em http://www.kufs.ac.jp/Brazil/delb/index. html

7 Mais informações disponíveis em http://embaixadadeportugal.jp/pt/lingua-portuguesa/concursos-de-eloquencia/

8 Em 2011, segundo o IPOR, esse número era de 13 docentes: 2 Portugueses, 3 Brasileiros e 8 Japoneses.

9 Por Dekasseguis entende-se o conjunto de cidadãos, descendente de japoneses que nasceu na América do Sul, e que emigrou para o Japão exercendo sobretudo trabalhos que requerem mão-de-obra pouco qualificada. 


\section{Referências bibliográficas}

AIRES, P.; S. Iyanaga e E. Muramatsu (2008), "Portufone: as novas tecnologias na didáctica do Português língua estrangeira", in Gabriel Antunes de Araújo e Pedro Aires (eds.), A Língua Portuguesa no Japão, São Paulo, Paulistana Editora, pp. 77-88.

ARAÚJO, G. A. (2008), "A Língua Portuguesa no Japão: um panorama", in Gabriel Antunes de Araújo e Pedro Aires (eds.), A Língua Portuguesa no Japão, São Paulo, Paulistana Editora, pp. 9-24.

COLAÇO, R. (2008), "Testemunho do ex-embaixador Português em Seul", Coreia do Norte. Um segredo de Estado. Disponível em https://coreiadonorte. wordpress.com/testemunho-do-embaixador-portugues-em-seul/ [Consultado em 22-12-2015]

FONSECA, F. (1985), o Português entre as línguas do mundo, Coimbra, Almedina.

HALL, J.W. (ed.) (1991), The Cambridge History of Japan, 4, Cambridge e Nova Iorque, Cambridge University Press.

INSTITUTO CAMÕES (2015), "Língua e ensino", Ensino do Português no estrangeiro - Ensino Superior. Disponível em: http://instituto-camoes.pt/epe-ensino-superior/root/lingua-e-ensino/epe-ensino-superior [Consultado em 27-12-2015]

MASON, R. H. P. (1997), A History of Japan, Rutland, Tuttle Co.

MOURA, V. G. (2005), "A Língua Portuguesa: um traço de união à roda do mundo", in Raquel Soeiro de Brito, Rui Pedro Julião e José Norberto Fernandes (orgs.), Atlas de Portugal, Lisboa, Instituto Geográfico Português. Disponível em http://dev.igeo. pt/atlas/index1.html [Consultado em 29-12-2015]

RAN, M. (2006), Aprender Português na China - O curso de licenciatura em Língua e Cultura Portuguesas da Universidade de Estudos Internacionais de Xangai: estudo de caso, dissertação de Mestrado, Aveiro, DLC-UA.
ROCHA, I. (2013), Português para alunos japoneses: propostas didáticas, dissertação de Mestrado, Lisboa, FCSH-UNL.

SOARES, M. G. (2013), "Português é a língua da moda e do emprego na China", Expresso [online]. Retirado a 30 de Outubro de 2013 de: http://expresso.sapo. pt/portugues-e-a-lingua-da-moda-e-do-emprego-na-china=f838497 [Consultado em 04-01-2016]

SUMIDA, I. (2008), "Um programa curricular de Língua Portuguesa equilibrado", in Gabriel Antunes de Araújo e Pedro Aires (eds.), A Língua Portuguesa no Japão, São Paulo, Paulistana Editora, pp. 67-76.

UNITED NATIONS STATISTICS DIVISION (2013), Composition of Macro Geographical (Continental) Regions, Geographical Sub-Regions, and Selected Economic and Other Groupings. Disponível em: http://unstats.un.org/unsd/methods/m49/m49regin.htm [Consultado em 21-12-2015]

UNIVERSIDADE DE ESTUDOS ESTRANGEROS DE BUSAN (2015), Faculdade de Estudos Ocidentais. Disponível em: http://www.bufs.ac.kr/English/03_college/ college_02.aspx [Consultado em 23-12-2015]

UNIVERSIDADE DE ESTUDOS ESTRANGEIROS DE HANKUK (2015a), Faculdade de Estudos Ocidentais. Disponível em: http://www.hufs.ac.kr/ user/hufsportuguese/un_1_b_1.jsp [Consultado em 23-12-2015]

UNIVERSIDADE DE ESTUDOS ESTRANGEROS DE HANKUK (2015b), Faculdade de Idiomas. Disponível em: .kr/user/hufsportuguese/un_2_b_2.jsp [Consultado em 23-12-2015]

YAN, Q. (2008), "Português Língua Estrangeira no continente Chinês: situação actual e alguns aspectos a melhorar", I Simpósio Mundial de Estudos da Língua Portuguesa, Universidade de São Paulo.

YUAN, A. (2012), Frequentar a Universidade: reflexões sobre o "ser estudante" na China e em Portugal, dissertação de Mestrado, Braga, ILCH-UM.

Submetido a 15/05/2016. Aceite para publicação a 19/09/2016.

Ânia Soeiro Matos (aniamatos@dlufl.edu.cn). Universidade de Línguas Estrangeiras de Dalian, Faculdade de Espanhol e Português, Departamento de Língua Portuguesa. 辽宁省大连市旅顺口区，旅顺南路西段6号，大连外国语大学 西葡语教研室, Código Postal: 116044, China. 